\title{
LESSON 47
}

MARGINS: Pica 20-70; Elite Type this sentence as many times as your teacher asks.

30-80.

Warm up

Increase Speed

35 wpm 2 minutes.

S20 - SI 1.05

$\mathrm{S} 21-\mathrm{SI} 1.11$

Improve Accuracy

30 wpm 2 minutes.

A17 - SI 1.21

A18 - SI 1.26

Test your Skill

2 minutes.

T8 - SI 1.28

Use double-line spacing.

UNIT 12
The crowd was out of hand but the Police were equal to the occasion and just linked up with more young troops to prize it into six moving parts.

It was good to get out of the snow and to sit in a nice warm seat in front of the hot coal fire. All he had to do was to dry out and rest. The two trips had been more than enough in the snow, which even now was still drifting. If it did not melt a little soon he would be stuck here and that was no good to him. He was keen to see the job over, for ever.

More by luck than skill the car did not leave the road, but it was a near thing. The two wheels on the near-side had all but gone over the side of the cliff as they had been forced wide on the last bend. It was no use. If they were to stand above an even chance of finishing they would have to $f i x$ the lights. In this area, there was little chance of it.

Always sit quite still when typing and do not sway about on your typing chair. Both feet should be flat on the floor while your body should be one hand span away from the front of the typewriter as you lean slightly forwards. Keep your eyes on the copy and make sure that you concentrate on the job at hand.

A good typist does not seem to be in a hurry, even though she may be typing at very high speeds. The secret is good technique and not making a move that is not necessary. She keeps her fingers over the Home Keys all the time and does not move about on her seat as she types. She keeps her elbows in always.

If you look at the printing on any bank note, issued by the Bank of England, you will find words printed on one side telling you that the Bank will pay you the value of the note. This promise, that is what it is, to pay you the value of the note is not strictly true to-day. When it was made it was possible to obtain payment in gold whereas now you can only obtain another note promising to pay.

\begin{tabular}{|l|l|l|l|l|l|l|l|l|l|l|l|}
1 & 2 & 2 & 3 & 4 & 5 & 6 & 7 & 8 & 9 & 10
\end{tabular} \mid

\section{LESSON 47}

